
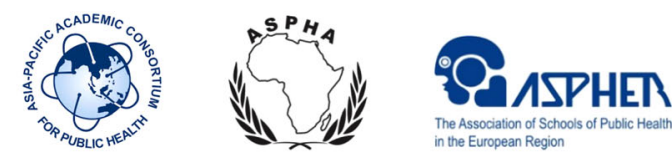

\title{
Global Network for Academic Public Health statement on the World Health Organization's response to the COVID-19 pandemic
}

\author{
John Middleton ${ }^{1} \cdot$ Philip Baba Adongo ${ }^{2} \cdot$ Wah-Yun Low $^{3} \cdot$ Laura Magaña $^{4}$
}

Received: 23 July 2020 / Accepted: 24 July 2020 / Published online: 25 September 2020

(C) Swiss School of Public Health (SSPH+) 2020

In the present global context, where there are widespread inequities in health and healthcare between and within countries, and public health systems frequently deprived of resources, a pandemic caused by a respiratory pathogen capable of human transmission was always going to have disastrous consequences. The World Health Organization (WHO) has been a key driver of response efforts throughout the COVID-19 pandemic and continues to lead the response despite having come under immense scrutiny globally (Buranyi 2020). As the disease burden intensifies and the associated crisis deepens, it is essential to contextualize the WHO's response within the scope of its responsibilities, the context of their mandates, and their level of maneuverability, as well as to appraise it in the

Prepared by Brian LH Wong, Royina Saha, Jose M MartinMoreno, John Middleton, Association of Schools of Public Health in the European Region (ASPHER).

John Middleton

john.middleton@aspher.org

1 Association of Schools of Public Health in the European Region (ASPHER), Brussels, Belgium

2 Association of Schools of Public Health in Africa (ASPHA), Accra, Ghana

3 Asia-Pacific Academic Consortium for Public Health (APACPH), Bangkok, Thailand

4 Association of Schools and Programs of Public Health (ASPPH), Washington, DC, USA backdrop of the knowledge and evidence unfolding around coronavirus pandemic. As the UN specialized agency and leading scientific body on health worldwide, now is the time to stand firmly behind the WHO and strengthen its efforts in handling the COVID-19 pandemic moving forward. Time spent in criticism of past actions risks us losing focus on tackling the appalling toll of ill health and death caused by the virus (Martin-Moreno and Middleton 2020).

\section{Combatting opinions alongside the virus}

The uncertainty and challenging nature of the pandemic itself has meant that the WHO has had to go beyond addressing typical public health concerns and simultaneously battle the oscillation of public opinion. There has always been some degree of misinformation circulating about pandemics and major outbreaks (Institute of Medicine (US) Forum on Microbial Threats 2007). However, the amount of half-truth and propaganda associated with COVID-19 has been much higher (Naughton 2020).

\section{The way forward}

What is clear from the WHO's range of interventions is their irrefutable role in nearly all aspects of the response to the pandemic (WHO 2020). If the WHO did not exist, we would inevitably have to create a body to pick up functions 
of global health governance. Therefore, the WHO should provide a comprehensive account of any threat to population health and to healthcare systems as well as provide contextual solutions when new evidence emerges. It is also clear that countries with particularly weak public health systems do look to the WHO for expertise and resources to support their responses. The WHO also plays a major role worldwide in addressing problems of non-communicable disease.

The WHO is not mandated to make decisions on behalf of its Member States. Rather, it is up to Member States themselves to formulate policies that are applicable and relevant to them. We have seen multiple instances of denial, reckless actions, and attempts to malign the WHO, stemming from a country's own inabilities, narrow political considerations, and short-term focus on the market economy, rather than on human lives and suffering. Moreover, the WHO's policy is fundamentally and essentially determined by its Member States themselves through the governing bodies that run the Organization.

As with any major health incident, after the dust settles, an inquiry or appraisal will be required to assess the actions taken and lessons to be learnt from them. The World Health Assembly has resolved to have an independent inquiry into the global response to the coronavirus pandemic (BBC News 2020). Pandemics have proven to be regularly occurring and inescapable phenomena over the course of human history. The twenty-first-century way of life renders pandemics more possible through the complex interactions of human and animal ecology as well as human social and economic activity. The existence of an international organization like the WHO does not eliminate the possibility of a pandemic, but it is a safeguard to protect lives. The WHO is the best chance we have to prepare for, respond to, and recover from future outbreaks and pandemics. As such, we need it to persist now, and during future outbreaks and pandemics more than ever. It is essential, however, that an inquiry is full, transparent, and honest. We as representatives of schools and programs of public health will comment critically, fully analyzing actions taken to ensure that mistakes are rectified and lessons are learned, for the future protection and improvement of health.

The Global Network for Academic Public Health (Global Network) is a convening body for academic public health leaders from around the world to share, learn, collaborate, to improve, and protect the health of the public and planet.

- We call on governments to commit to a new era of openness, information sharing and mutual support, to combat the COVID-19 pandemic, and future threats to the health of the world. We urge them to make a renewed commitment to global health governance.

- We call on governments to maintain financial and material support to the WHO during and following the pandemic.

- The Global Network calls on regional and national associations, societies, and schools of public health worldwide to continue to mobilize academic support in the fight against COVID-19, in collaboration with WHO offices across the globe.

- We call for solidarity across, within, and between continents, countries, associations, and schools of public health in support of the WHO. We call on donors to provide funding which is less bound to specific projects, so it can be used more flexibly by the WHO.

- The Global Network is committed to stand in solidarity with, reinforce, and coordinate the efforts of our members and member associations of public health worldwide as well as to provide evidence and make expertise available for the independent inquiry as requested by the WHO.

\section{References}

BBC News (2020) Coronavirus: World Health Organization members agree response probe. https://www.bbc.co.uk/news/world52726017

Buranyi S (2020) The WHO v coronavirus: why it can't handle the pandemic. https://www.theguardian.com/news/2020/apr/10/ world-health-organization-who-v-coronavirus-why-it-cant-han dle-pandemic

Institute of Medicine (US) Forum on Microbial Threats (2007) Ethical and Legal Considerations in Mitigating Pandemic Disease: Workshop Summary. https://www.ncbi.nlm.nih.gov/books/ NBK54167/

Martin-Moreno JM, Middleton J (2020) Now is not the time to undermine the World Health Organisation. https://blogs.bmj. $\mathrm{com} / \mathrm{bmj} / 2020 / 05 / 05 /$ now-is-not-the-time-to-undermine-theworld-health-organization/

Naughton (2020) Fake news about Covid-19 can be as dangerous as the virus. https://www.theguardian.com/commentisfree/2020/ mar/14/fake-news-about-covid-19-can-be-as-dangerous-as-thevirus

WHO (2020) Timeline of WHO's response to COVID-19. https:// www.who.int/news-room/detail/29-06-2020-covidtimeline

Publisher's Note Springer Nature remains neutral with regard to jurisdictional claims in published maps and institutional affiliations. 